\title{
Organic Template Free Synthesis of ZSM-5 from Calcinated Indonesian Kaolin
}

\author{
Hartati $^{1, \text { a) }}$, Alfa Akustia Widati ${ }^{1, b)}$, Alfinda Novi Kristanti ${ }^{1, c)}$, \\ Aning Purwaningsih ${ }^{1, d)}$, Alfiani ${ }^{1, e)}$ \\ ${ }^{1}$ Department of Chemistry Faculty of Sciences and Technology \\ Universitas Airlangga, Surabaya 60115, Indonesia \\ a)Corresponding Author's E-mail: hartati@fst.unair.ac.id \\ b)alfaakustia@fst.unaur.ac.id \\ c)alfinda-n k@fst.unair.ac.id \\ d)aning-p@fst.unair.ac.id \\ e)alfiani19@ymail.com
}

\begin{abstract}
A pure ZSM-5 has been synthesized from calcinated kaolin without organic template. The synthesized samples were characterized using X-ray diffraction (XRD), Fourier Transform Infrared (FTIR) spectroscopy, nitrogen adsorption/desorption technique, and Transmission Electron Microscopy (TEM). The results showed that microporous ZSM-5 obtained by silica adding through three-step crystallization at $100-120-150{ }^{\circ} \mathrm{C}$ for $24 \mathrm{~h}$ respectively.
\end{abstract}

\section{INTRODUCTION}

ZSM-5 zeolite generally synthesized using commercial chemicals as silica and alumina sources. Tetraethylorthosilicates (TEOS) was the most chemical used as silica source [1,2]. Other materials also used as silica sources like ludox [2], water glass [3], and $\mathrm{SiO}_{2}$ hydrogel [4]. As alumina source, some researchers used of aluminum isoproxide (AIP) [5] aluminum sulphate $\left(\mathrm{Al}_{2}\left(\mathrm{SO}_{4}\right) \cdot 18 \mathrm{H}_{2} \mathrm{O}\right)$ [3] sodium aluminates $\left(\mathrm{NaAlO}_{2}\right)$ [5], and other chemicals contained aluminum.

On the other hand, ZSM-5 could be synthesized using natural materials as starting materials, such as rectorite [6], rice husk ash [7], and kaolin [8,9]. The utilization of natural materials as a precursor in zeolite synthesis is more advantageous than chemicals because it is more economical,

ZSM-5 was typically synthesized using organic template as MFI structure directing agents, like tetrapropylammonium bromide, $\mathrm{TPABr}$ [6] or tetrapropylammonium hydroxide, TPAOH [5]. The synthesis method without MFI structure directing agents have been successfully developed and conducted [9], however it still required surfactant cethyltrimethylammonium bromide (CTAB) as mesophase agent. In the previous research, we have been successfully prepared the high crystallinity of ZSM-5 from Indonesian kaolin through treatment with the addition of sodium fluoride [10]. 